\title{
O COMPASSO, O ESQUADRO E A ORDEM DISCRETA: PERFIL SOCIOLÓGICO DOS GRÃO-MESTRES DA MAÇONARIA PARANAENSE ${ }^{1}$
}

Tiago Valenciano ${ }^{2}$

- Enviado em 15/04/2016

- Aprovado em 20/05/2016

\section{RESUMO}

O presente trabalho tem como destino sumário analisar coletivamente, a partir do método prosopográfico, o perfil dos Grão-Mestres do Grande Oriente do Brasil - Paraná (GOB/PR), da Grande Loja do Paraná (GLP) e do Grande Oriente do Paraná (GOP), com o objetivo de delimitar uma elite estratégica, constituída a partir de indivíduos e capitais sociais específicos, como profissão, carreira maçônica e inserção social. Assim, a questão desta trabalho (qual é o perfil sócioprofissional dos grão-mestres da maçonaria paranaense) destina-se a compreender este grupo social estratégico, medindo os limites da presença e atuação social coesa no Paraná. Em primeiro lugar, efetuamos um balanço sobre a maçonaria no Paraná e seu desenvolvimento. Em seguida, abordamos as possibilidades do método prosopográfico e de seu uso como técnica sociológica. Adiante, há o estudo dos perfis destes indivíduos, investigando os padrões de recrutamento dos maçons em questão, no que tange à origem social, profissional, carreira na instituição e a relação das respectivas atividades profissionais com a sociedade. Por fim, um exame detido dos resultados será realizado - ainda sob a égide do problema de pesquisa: em qual medida a biografia coletiva dos Grão-Mestres se relaciona com a sociedade paranaense quanto à posição social, profissional, política e institucional.

Palavras-chave: Maçonaria. Prosopografia. Maçonaria paranaense. Grão-Mestres.

\section{INTRODUÇÃO}

Maçonaria. Uma instituição instigante. Esta é a primeira motivação para o andamento deste trabalho, intitulado "O compasso, o esquadro e a ordem discreta: perfil sociológico dos grãomestres da maçonaria paranaense", objeto deste texto. Esta instituição - citada por seus membros

\footnotetext{
${ }^{1}$ Uma versão preliminar desse trabalho foi apresentada no GT1: INSTITUIÇÕES E PODER: PARENTESCOS E GENEALOGIAS do VII Seminário Nacional de Sociologia e Política da UFPR realizado de 11 a 13 de maio de 2016 em Curitiba.
}

2 Doutor em Sociologia pela UFPR, Mestre e Graduado em Ciências Sociais pela UEM. E-mail: tiagovalenciano@gmail.com 
como milenar ${ }^{3}$, relembrado inclusive passagens bíblicas - em uma categorização mitológica (LÉVISTRAUSS, 1978, p. 34), é objeto de uma diversidade de trabalhos escritos por maçons e de grupos que a abominam. Editoras especializadas, grupos de pesquisas, lojas maçônicas, ex-integrantes, instituições religiosas (em sua maioria igrejas evangélicas, de forma mais aberta na atualidade e a igreja católica, do Século XIV em diante) publicam materiais alusivos à maçonaria. Em uma breve pesquisa na internet é possível verificar que se torna praticamente impraticável efetuar uma contagem e classificação destas edições sobre o assunto. Apenas quando restringirmos a busca a trabalhos acadêmicos que a cifra de pesquisas é restrita, uma vez que o interesse das ciências humanas sobre a maçonaria é algo recente. São duas as revistas acadêmicas que versam sobre a instituição: Fraternidade in Praxis, com a primeira edição em 2013; e Ciência \& Maçonaria, editada pela primeira vez no mesmo ano.

Se considerarmos a produção científica acadêmica sobre o tema podemos listar o número de trabalhos. Somente a partir da década de 1990 é que a maçonaria atraiu a comunidade acadêmica nacional $^{4}$, com pesquisas direcionadas para a historiografia. Neste sentido, verificamos dois eixos temáticos dominantes: a atuação política da instituição e seus membros no Brasil da segunda metade do século XIX até a primeira metade do início do Século XX; e a mesma participação em movimentos atribuídos aos maçons, como a Independência Nacional (CORDEIRO, 2008) e a Proclamação da República (COSTA, 2003; CLEBERSON, 2012).

Assim, em uma análise rápida sobre esta produção sobre a maçonaria, questionamos: quais são as possibilidades de efetuar um trabalho acerca do tema, utilizando a sociologia como aporte de pesquisa? E mais: quais são as chances de executar uma pesquisa relacionando a sociologia, a maçonaria e o Estado do Paraná? A partir destas questões, procuramos estabelecer um paralelo entre os assuntos. A dificuldade de pesquisar academicamente a maçonaria - imposta pela escassa bibliografia e acesso aos templos maçônicos - fez com que a instituição fosse estudada apenas a partir de materiais devidamente publicados. Igualmente, a sociologia pode oferecer subsídios de análise institucional (o uso da prosopografia e da denominada sociologia do campo e das estruturas sociais, de Bourdieu). Por fim, o Paraná se constituiu como recorte geográfico e temporal do objeto da pesquisa, visando delimitar o horizonte de investigação. Destacamos, portanto, o ineditismo da associação entre sociologia e maçonaria, uma seara pouco (ou talvez ainda não) explorada pelos

\footnotetext{
${ }^{3}$ Conforme definição do Grande Oriente do Brasil. Disponível em: <http://gob.org.br/index.php?c=4644> Acesso em: 29 ago 2015.
}

${ }^{4}$ O trabalho de Carvalho (2007) analisa esta produção. 
cientistas sociais, seja na antropologia, sociologia, ciência política ou aproximação destas áreas do conhecimento.

Considerando o trinômio maçonaria / sociologia / Paraná, procuramos estabelecer um objeto de possível densidade sociológica e ainda não estudado: os Grão-Mestres, isto é, a elite políticoinstitucional da maçonaria no Estado. Nossa tese é a seguinte: analisando coletivamente, a partir do método prosopográfico, o perfil dos Grão-Mestres do Grande Oriente do Brasil - Paraná (GOB/PR), da Grande Loja do Paraná (GLP) e do Grande Oriente do Paraná (GOP), podemos visualizar uma elite estratégica, constituída a partir de indivíduos com capitais sociais específicos, como profissão, carreira maçônica e inserção social. Logo, a questão deste trabalho (qual é o perfil sociológico dos grão-mestres da maçonaria paranaense) tem como propósito compreender este grupo social estratégico, medindo os limites da presença e atuação social coesa no Paraná.

Pretendemos explicar a metodologia adotada (a prosopografia), articuladas aos conceitos de campo, habitus, capital simbólico e trajetória social de Pierre Bourdieu e autores correlatos. Para tal, sinalizamos que o estudo de perfis coletivos, em grupos sociais delimitados no tempo e no espaço, tende a auxiliar na assimilação da atuação dos seus membros - neste caso, os Grão-Mestres do GOB/PR, GLP e GOP. Além disso, os capitais sociais e a estrutura societária em que estes indivíduos pertencem serão explorados a partir dos conceitos de campo e habitus, de Bourdieu. O argumento apresentado é que a maçonaria constitui-se em um campo próprio de social, em que as regras destes ocorre $\mathrm{m}$ articuladas com os aspectos intra e extrainstitucionais, com agentes jogando o jogo do campo em busca de melhorar suas posições sociais, a partir de capitais simbólicos.

Analisamos, ainda, a biografia coletiva dos Grão-Mestres das potências citadas, em um esforço de somar estas biografias coletivas e, portanto, perpetrar a prosopografia e as trajetórias sociais, bem como oferecer indícios para a resolução da tese proposta. Para isso, optamos pelo estudo detido de cada trajetória dos Grão-Mestres e seus componentes, como o município de origem, a escolaridade, a relação profissão/ocupação, a atividade política das lideranças maçônicas do Paraná e as conexões interinstitucionais existentes.

Nossa tese funda-se no argumento de que os Grão-Mestres da maçonaria paranaense tem um perfil sociológico em que suas trajetórias sociais foram constituídas nas relações estabelecidas dentro do campo da maçonaria, com o habitus adquirido com o tempo, articulado interna e externamente à este campo, além de uma trajetória marcada por alta escolarização, postos ocupacionais tradicionais, atividade política presente e perpetuação em outras instituições sociais o que caracteriza, em suma, o itinerário percorrido para que um maçom se torne Grão-Mestre, isto é, liderança estadual da instituição no Paraná. 


\section{A MAÇONARIA ORGANIZADA NO PARANÁ}

O percurso das potências maçônicas do Paraná exprime uma espécie de radiografia da presença da instituição no Estado. A partir de 1837, com a fundação da primeira loja maçônica e, posteriormente, a implementação da Delegacia do Grande Oriente do Brasil em 1902, a maçonaria paranaense rumou com a finalidade protagonista de autonomia, de independência institucional e organização regional. A trajetória de cisões, fusões e anseios de emancipação face ao poder central do GOB expressam a aspiração por uma maçonaria estritamente paranaense. Ainda que este objetivo não fosse alcançado completamente com o GOB/PR, por exemplo, tanto a GLP quanto O GOP possuem soberania quanto a organização interna, administração e fundação de lojas, por exemplo.

No esquema abaixo, podemos esmiuçar esta espécie de "teia da maçonaria", sua perpetuação e continuidade:

Figura 1. Rupturas na estrutura da maçonaria no Paraná.

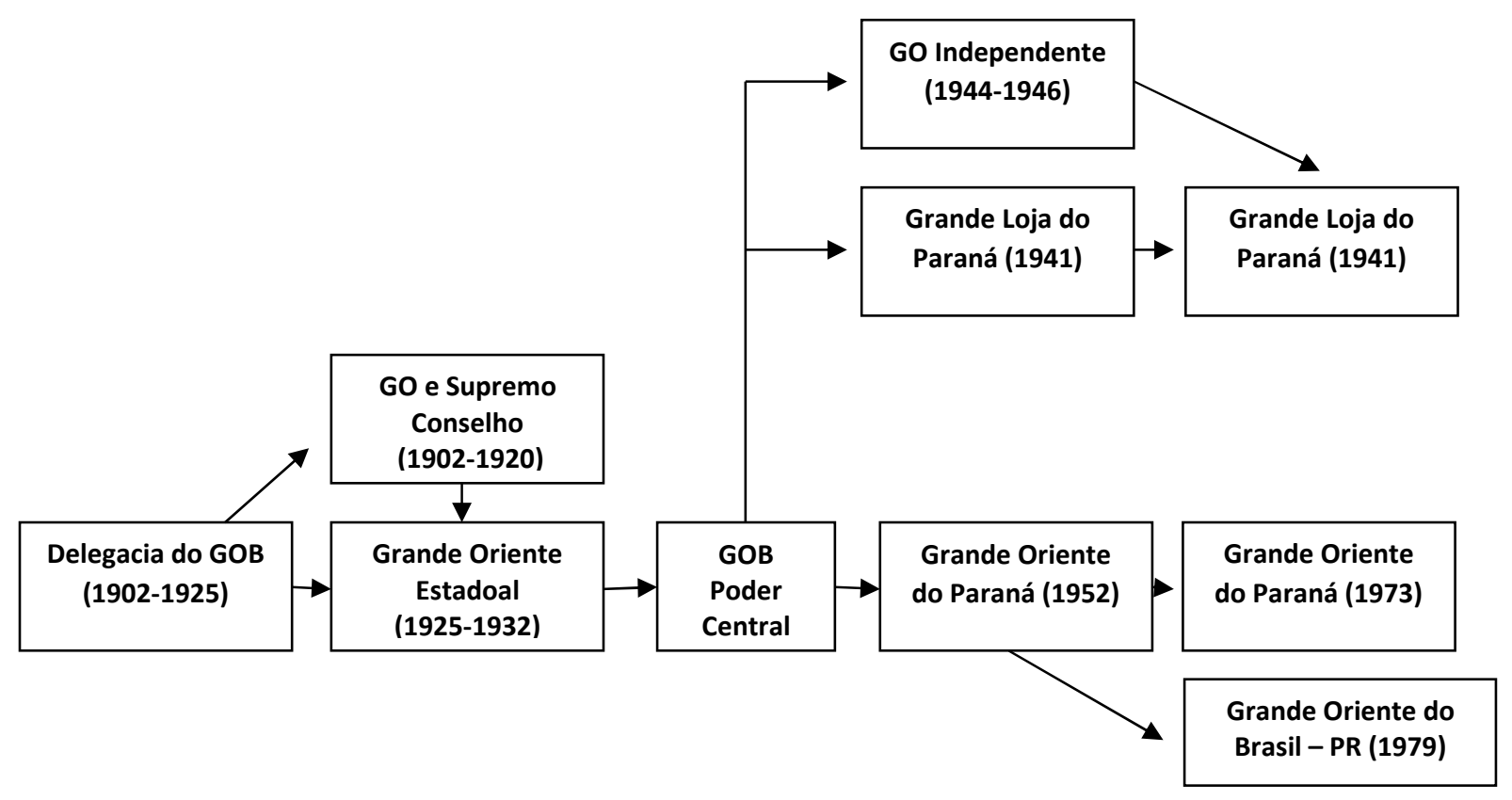

Fonte: o autor (2015) 
Vale ressaltar que, atualmente, o Grande Oriente do Brasil-Paraná (GOB-PR) possui $122^{5}$ lojas e cerca de 3.800 maçons; o Grande Oriente do Paraná (GOP) possui $161^{6}$ lojas maçônicas e aproximadamente 4.800 maçons; e a Grande Loja do Paraná (GLP) $163^{7}$ lojas maçônicas, com cerca de 4.500 integrantes. Estes números totalizam, assim, 446 lojas e 13.100 maçons no Estado do Paraná.

Em um resumo sobre a genealogia da maçonaria regional - ou ainda, a "teia da maçonaria" no Paraná, apontamos as três principais características acerca do assunto, sendo:

1) O notado desejo pela autonomia institucional face ao poder central do Grande Oriente do Brasil. Grande parte das cisões estaduais surgiram a partir da busca pela liberdade de administração regional sobre os assuntos da instituição, como nos casos da criação da Delegacia do GOB no Paraná (1902), do Grande Oriente e Supremo Conselho do Paraná (1902) e do próprio Grande Oriente do Paraná (1952);

2) As disputas pelo controle da maçonaria, ou seja, pelo governo de cada grupo dominante internamente e, por conseguinte, as divergências de posicionamento sobre assuntos da instituição casos da criação do Grande Oriente Independente do Paraná (1944) e da Grande Loja do Paraná (1941);

3) A presença dos Grão-Mestres em posições estratégicas da estrutura da sociedade paranaense, um dos intuitos deste trabalho. Já apontamos a participação de Grão-Mestres no cenário político estadual do final do Século XIX até o início do Século XX. Adiante, quando analisarmos o perfil sócio-profissional dos Grão-Mestres do GOB/PR, GLP e GOP, pretendemos avaliar estes perfis, destacando que tipo de elite estratégica estas lideranças passaram a compor.

Assim, este panorama auxilia na compreensão do papel desempenhado por estas potências no âmbito maçônico paranaense e, sobretudo, oferece recursos para entender a trajetória social dos Grão-Mestres pesquisados, relativamente à participação social em outras instituições congêneres, a atuação profissional, a formação acadêmica e o engajamento institucional, entre outros. Portanto, esta radiografia da genealogia maçônica no Estado poderá apontar elementos diversificados sobre o perfil dos Grão-Mestres, que será efetuado adiante.

5 Portal do GOB-PR na internet. Disponível em: < http://gobpr.org.br/site/index.php?option=com_content\&view=article\&id=166\&Itemid=151>. Acesso: 05 mar 2016.

${ }^{6}$ Portal do GOP na internet. Disponível em: < http://gop.org.br/?sec=institucional\&page=lojas\&tipo=3>. Acesso: 05 mar 2016.

7 Portal da GLP na internet. Disponível em: < http://glp.org.br/site/grande-loja-pagina-mae/lojas-da-jurisdicao/> Acesso: 05 mar 2016. 


\section{ANÁLISE DOS PERFIS: UM ETUDO DO CAMPO DA MAÇONARIA}

O presente trabalho teve como destino sumário analisar coletivamente, a partir do método prosopográfico, das noções de trajetória social, campo, habitus e capital (segundo Bourdieu) o perfil dos Grão-Mestres do Grande Oriente do Brasil - Paraná (GOB/PR), da Grande Loja do Paraná (GLP) e do Grande Oriente do Paraná (GOP), com o objetivo de delimitar uma elite estratégica, constituída a partir de indivíduos e capitais sociais específicos, como profissão, escolaridade e inserção político-social. Assim, a questão deste trabalho (qual é o perfil sociológico dos GrãoMestres da maçonaria paranaense) destina-se a compreender este grupo social estratégico, medindo os limites da presença e atuação social coesa no Paraná.

Em nosso itinerário, ao examinarmos a organização e estrutura interna da maçonaria, verificamos a reprodução do modelo do Estado brasileiro (a possível tripartição do poder entre Executivo, Legislativo e Judiciário $^{8}$ ) em seu interior. Da mesma forma, descobrimos a relação entre as potências maçônicas, uma espécie de organização nacional e/ou estadual que comanda as atividades da instituição em determinada região, e as lojas maçônicas, espaços locais com relativa autonomia interna. O foco é explicar, a partir da estrutura interna, os caminhos percorridos por um maçom que deseja atingir o cargo de Grão-Mestre, bem como a complexidade das relações internas, fundadas em mecanismos próprios do campo de ação social - que, com suas disputas internas, ao mesmo tempo que as regula, também sofre as pressões exteriores. (LAHIRE, 2002, p. 47-48).

Em relação à origem e ao desenvolvimento da maçonaria paranaense e todas as subdivisões ocasionadas desde o início do Século XX, reforçamos o argumento de que a maçonaria possui um pensamento, uma ideologia coesa, mas internamente dispõe de variações estruturais. A direção deste trajeto pautou-se em retratar a maçonaria articuladamente com a história do Paraná, seu desenvolvimento e a ocupação do território, ora historicamente e socialmente falando, ora de forma "maçônica", envolvendo assim as disputas, trocas de comando e de sede na instituição. A radiografia da maçonaria no Paraná se concentrou em três pontos: 1) a vontade de autonomia dos organismos estaduais face ao poder nacional; 2) as disputas pelo controle do comando da maçonaria; 3) e a posição estratégica dos Grão-Mestres na sociedade paranaense, sobretudo até a primeira metade do Século XX.

A aplicabilidade do método prosopográfico à sociologia de Pierre Bourdieu e autores correlatos articula o movimento deste artigo. A defesa da prosopografia perpassa pela ideia de

\footnotetext{
${ }^{8}$ Acerca da tripartição do poder, ver: VALENCIANO, Tiago \& LEAL E SILVA, Rafael Egídio. Política Brasileira: como entender o funcionamento do Brasil. Astorga: Editora Sahar, 2015.
} 
trajetória social, uma vez que o método só pode ser aplicado a partir do momento em que há o estudo das biografias coletivas considerando a análise das trajetórias sociais, isto é, não somente na coleta de dados dispersos, desunidos e sem articulação entre si (BOURDIEU, 1996). A proposta do uso da prosopografia ainda é aceito, visto que:

\begin{abstract}
De uma maneira geral, podemos dizer que as estruturas políticas e sociais de certos grupos, fenômenos como a continuidade e a descontinuidade de sistemas políticos, de instituições eclesiásticas ou seculares, a ação política, a mobilidade social, a transformação social e tantos outros, não podem ser analisados com precisão sem o conhecimento prévio das pessoas. É apenas graças a este conhecimento que é possível relacionar diferentes grupos, considerando que certos indivíduos sem encontram frequentemente no campo de ação de mais de um grupo. $\mathrm{O}$ fato de que, neste contexto, as pessoas tenham moldado instituições e tenham sido por elas também impregnadas (ainda que de maneiras bem diversas), deve ser levado em consideração em cada análise prosopográfica (BULST, 2005, p.58).
\end{abstract}

Ou seja, somente a partir da pesquisa quanto às trajetórias sociais, munida pelo método prosopográfico, é possível analisar grupos sociais coesos ou dispersos na sociedade, bem como seu campo de ação social específico. Neste sentido, os conceitos e categorias de Bourdieu em relação ao habitus, campo, capital simbólico e trajetória social (BOURDIEU, 1983; 1986; 1989; 1990; 1994; 1998; 2003; 2009) são fundamentais para a compreensão da análise prosopográfica destes GrãoMestres e seus desdobramentos: a atuação profissional/ocupacional, a formação escolar, a participação política e os vínculos institucionais estabelecidos.

A análise sociológica enfoca a metodologia bourdieusiana, aliada à prosopografia, proporcionando subsídios para responder a questão motriz deste artigo: o perfil sociológico dos Grão-Mestres da maçonaria paranaense forma, assim, uma elite estratégica nos últimos anos que interfere socialmente, economicamente, culturalmente e politicamente na sociedade em que está ambientada, isto é, no Estado do Paraná? Este questionamento abriu os caminhos para a análise em conjunto (prosopográfica) destes indivíduos, reunindo as informações coletadas - o que garantiu os elementos para a construção da quinta e última parte, direcionada, então, para a consolidação coletiva e demonstração das trajetórias sociais destes Grão-Mestres.

O primeiro aspecto analisa a relação entre capital e interior quando da escolha dos GrãoMestres. O resultado é a migração do capital político dentro do campo da maçonaria para o interior conforme houve a expansão do território paranaense (BALHANA, A.P.; MACHADO, B.P.; WESTPHALEN, C.M., 1969), algo presente na liderança do Grande Oriente do Brasil-Paraná e do Grande Oriente do Paraná - porém pouco observado na Grande Loja do Paraná. Relativamente ao extrato do perfil sociológico destes indivíduos, $28 \%$ destes pertenciam ao interior, contra $72 \%$ de liderança da capital. Este resultado espelha o observado na direção do Poder Executivo do Estado, 
com as forças políticas centradas a partir das famílias que comandam o poder no Paraná (OLIVEIRA, 2001;2012) - em sua maioria presentes na denominada "classe dominante tradicional", isto é, aquela presente na cúpula do poder estadual (concentrado, na sede administrativa, ou seja, em Curitiba).

Quanto à escolaridade dos Grão-Mestres, cursar o ensino superior é quase que uma unanimidade entre estes personagens. São $90 \%$ os maçons que frequentaram as salas de aula no ensino superior, obtendo as profissões que serão analisadas adiante, contra $4 \%$ que finalizaram o ensino médio e $6 \%$ que não obtivemos informações precisas. Isto reforça o argumento de que a liderança da maçonaria reflete a hipótese de que seus integrantes formam a classe dominante da sociedade. Ou seja, se espelharmos a partir da liderança da maçonaria paranaense o maçom do Estado, este tende a frequentar o ensino superior, sendo, portanto, um habitus adquirido exterior ao campo social da maçonaria, mas que é importante para o recrutamento social de integrantes para a instituição.

Acerca da origem profissional e ocupacional, há um grupo de autores que optaram em estudá-la ${ }^{9}$. Das variadas análises, optamos pela classificação de Rodrigues (2002), que diferencia a profissão, obtida pela escolarização, da ocupação, em alguns casos divergente da profissão. $\mathrm{O}$ ranking das profissões é liderado pelos advogados, com $27 \%$ dos casos, seguido dos militares (25\%); profissionais liberais diversos (14\%); servidores públicos, comerciários e médicos com $8 \%$ cada; sem classificação definida com $6 \%$ e professores com $4 \%$. Percebe-se que, além das forças armadas - com um quarto dos Grão-Mestres, os advogados lideram a formação profissional da liderança da maçonaria no Paraná. Esta tradição dos bacharéis na formação cultural brasileira é uma tradição da eclosão do liberalismo no Brasil Imperial e, neste sentido, o bacharel integrava um espaço acadêmico de disputas ideológicas e políticas, na tentativa de recrutar os intelectuais da sociedade brasileira:

Assim no contexto de uma vida acadêmica controvertida, agitada, heterogênea e ambígua, constituída nos interiores das associações e institutos científicos, políticos, literários e filosóficos, o jornalismo foi tanto o espaço que possibilitou a inserção do acadêmico/ bacharel em loci diversos daqueles exclusivamente ditados pela ciência do Direito, quanto o espaço destinado à criação de uma inteligentzia, da qual se recrutaram os intelectuais da sociedade brasileira oitocentista [...]. O primeiro jornal acadêmico foi fundado a 4 de abril de 1830 [e] [...] esta imprensa nasceu da necessidade de divulgar ideias liberais. (ADORNO, 1988, p. 163).

\footnotetext{
${ }^{9}$ Segundo Perissinotto (2003, p. 5): "Trata-se de um tema importante porque nos permite trabalhar com as seguintes questões recorrentes na literatura: 1) quão estreita ou quão ampla, isto é, quão democrática ou quão "elitista" é a base de seleção das elites políticas [..]; b) é possível estabelecer uma relação explicativa entre ocupação profissional e comportamento político?; c) existem "profissões" para a política, isto é, aquelas que favorecem a carreira política e o acesso aos cargos políticos?"
} 
Além da explicação sobre a presença dos bacharéis - em especial os e direito - na formação da sociedade brasileira do Século XIX e sua herança para o Século XX, há a participação dos militares neste processo. Assim, qual é a importância da militarização da sociedade? Segundo Santin e Lorenzoni (2013, p. 51), “A intensa disputa pelo poder entre os grupos e classes sociais condicionou a militarização das sociedades locais e até mesmo regionais, abrindo precedentes à instauração de um forte aparelho repressor estatal". Ou seja, o binômio bacharel em direito/militar formava uma equação fundamental para o entendimento do Brasil do início do Século XX, que se perpetua até hoje na trajetória social dos Grão-Mestres estudados.

A predominância de bacharéis e militares na constituição do perfil profissional da maçonaria pouco se altera quando observamos a questão ocupacional dos Grão-Mestres. Em primeiro lugar há a predominância dos advogados ou das atividades diretamente ligadas ao exercício do direito (tais como promotores, juízes, desembargadores ou serventuários da justiça), com $24 \%$. Se considerarmos apenas os advogados que continuaram a exercer a profissão em sua ocupação este número é de $12 \%$. O segundo lugar é dos militares, com 20\%, seguidos por: professores (14\%); comerciários (12\%); políticos profissionais (10\%); médicos (6\%); profissionais liberais (5\%); servidores públicos (4\%); e sem classificação (5\%).

Os advogados e as derivações da profissão (24\%), os militares (20\%) e os políticos profissionais (10\%) determinam o que denominamos triunvirato ocupacional da maçonaria. Notase que excluímos tantos os professores quanto os comerciários desta classificação - ainda que possuam índices maiores do que dos políticos profissionais. Este motivo justifica-se pela atividade de professor exercida pelos Grão-Mestres, às vezes consequência de outra ocupação mais relevante. Quanto aos comerciários, esta categoria abarca diversos tipos de profissionais ligados ao comércio, como empresários, industriais e funcionários. Além disso, a intensidade da atividade política (com a tentativa do exercício, pelo menos), representa a predisposição dos maçons em atuar politicamente. Portanto, a escolaridade, profissão e ocupação destes indivíduos são marcadas pela inserção na advocacia, no militarismo e na política.

Como exposto, a atividade política é intensa e marcante na maçonaria, principalmente em seu apogeu no Século XIX. Ao analisarmos a inserção política dos Grão-Mestres, 43\% destes possuíram alguma experiência com a política em suas trajetórias sociais, desde o ato de se filiar a um partido político até o exercício de uma função pública, seja esta eletiva ou não. Ainda que a maioria (57\%) não possua este tipo de relacionamento, justificamos a baixa adesão dos GrãoMestres da Grande Loja do Paraná à participação política, bem como a especialização dos campos 
(BOURDIEU, 1990), fatores este que contribuíram para a inserção de maçons em menor intensidade nos últimos anos. Ainda assim, não podemos desprezar a presença da maçonaria na política, uma vez que os manifestos do Grande Oriente do Brasil (2016) e da Confederação Maçônica do Brasil (2013), enunciados neste trabalho, demonstram a valorização do assunto política para os maçons e, sobretudo, para seus líderes.

Por fim, a vinculação institucional reflete que $47 \%$ dos Grão-Mestres possuíram algum tipo de conexão interinstitucional, refletindo assim a tendência em buscar mais do que um espaço de sociabilidade. Esta sociabilidade pode ser considerada burguesa, pois os resultados demonstram que os Grão-Mestres frequentam locais predominantemente da classe social dominante. Em primeiro lugar, com 27\%, há as entidades classistas (demonstrando o interesse nas questões vinculadas à profissão/ocupação). Seguem-se as entidades desportivas (26\%), as entidades filantrópicas e educativas (cada uma com 20\%) e as instituições congêneres à maçonaria (7\%). Logo, se verificarmos as quatro primeira colocadas, temos: 1) o interesse pelos desdobramentos profissionais/ocupacionais; 2) os clubes ${ }^{10}$ desportivos, frequentados normalmente por pessoas de classe social abastada; 3 ) as entidades filantrópicas - também com integrantes da classe dominante, afinal, estas entidades tem o mesmo perfil de atividade assistencial que a maçonaria (Lions International, Rotary Clube, por exemplo); 4) e as entidades educacionais, como centros de pesquisa tradicionais no Paraná (o caso do Centro de Letras do Paraná, fundado em 1912 representa nosso argumento).

\section{CONSIDERAÇÕES FINAIS}

O perfil sociológico dos Grão-Mestres pode ser considerado, desta forma, de predominância do domínio político da capital diante do interior, de alta escolaridade, com um triunvirato profissional/ocupacional formado pelos advogados (a tradição dos bacharéis), pelos militares e políticos profissionais, uma intensidade mediana na participação (ou pelo menos tentativa de) política e, da mesma forma, as conexões estabelecidas em relação aos vínculos institucionais.

Estes Grão-mestres da maçonaria paranaense têm um perfil sociológico em que suas trajetórias sociais foram constituídas nas relações estabelecidas dentro do campo da maçonaria, com

\footnotetext{
${ }^{10}$ A origem da palavra clube provém do inglês $c l u b$, que é um grupo de pessoas associadas com o mesmo tipo de opinião, seja ela desportista, cultural, artística, política ou filantrópica, por exemplo.
} 
o habitus adquirido com o tempo, articulado interna e externamente a este campo, além de uma trajetória marcada por alta escolarização, postos ocupacionais tradicionais, atividade política presente e perpetuação em outras instituições sociais - o que caracteriza, em suma, o itinerário percorrido para que um maçom se torne Grão-Mestre, isto é, liderança estadual da instituição no Paraná. Tal posição de protagonismo só existe em virtude das disputas do campo, o que marca, também, o perfil deste:

Em seguida, a partir do âmago da autonomia do campo, devemos delinear as relações entre as posições ocupadas, alocadas, deslocadas pelos agentes e pelos grupos; esmiuçar a trama sincrônica de um determinado momento do campo, resultado de uma história de lutas e conflitos pelo poder legítimo e legitimado pelos próprios agentes envolvidos. Por fim, do resultado destes embates reais e históricos, conseguimos a tessitura dos habitus coletivos dos grupos em embate, cujas variações individuais não fazem mais que confirmar, desviando-se às vezes do mainstream social, a característica fortemente coletiva das carreiras individuais dos agentes. (MONTAGNER, 2007, P. 254)

Ou seja, ainda que ocorram as disputas internas dentro do campo social da maçonaria, estas auxiliam na formação das trajetórias sociais estabelecidas, que são importantes para a compreensão do andamento destes grupos:

Em suma, perseguir uma trajetória significa acompanhar o desenrolar histórico de grupos sociais concretos em um espaço social definido por esses mesmos grupos em suas batalhas pela definição dos limites e da legitimidade dentro do campo em que se inserem. Seguramente a origem social é um holofote poderoso na elucidação dessas trajetórias, pois o habitus primário, devido ao ambiente familiar, é uma primeira e profunda impressão social sobre o indivíduo, que sofrerá outras sedimentações ao longo da vida. (MONTAGNER, 2007, p. 257)

A origem social destes Grão-Mestres é de uma classe social em que a união dos agentes desta classe possuem condições homogêneas, produzindo um habitus próprio, garantido com a posse de bens ou poderes que serão incorporados ao habitus da classe - neste caso, a dominante, considerando os elementos das trajetórias sociais destes indivíduos (alta escolaridade, inserção política e social aparente).

Assim, ao analisarmos coletivamente este perfil sociológico dos Grão-Mestres, apontamos a existência de uma elite estratégica, constituída a partir de indivíduos com capitais sociais específicos, como profissão, carreira maçônica e inserção social que ainda interessam para a constituição da sociedade paranaense, estabelecendo uma interconexão entre o campo social da 
maçonaria e os demais campos existentes (como a política, o campo das instituições sociais e as posições ocupacionais estratégicas ${ }^{11}$ - vide a política e a questão militar).

\section{REFERÊNCIAS}

A BÍBLIA. Tradução ecumênica: São Paulo: Paulinas, 2002.

ABRUCIO, Fernando Luiz. SAMUELS, David. A nova geopolítica dos governadores. Revista Lua Nova, n. 40-41, 1997, p-137-166.

ADORNO, Sérgio. Os aprendizes do poder: bacharelismo liberal na política brasileira. São Paulo: Paz e Terra, 1988.

ALVES, Alessandro Cavassin. A província do Paraná (1853-1889). A classe política. A parentela no governo. Tese (doutorado). Curitiba: Programa de Pós-Graduação em Sociologia, Universidade Federal do Paraná, 2014.

ASSIS CARVALHO, Francisco de. Cadernos de estudos maçônicos: ritos e rituais. Londrina, A Trolha, 1993.

AZEVEDO, Mario Luiz Neves de. Espaço Social, Campo Social, Habitus e Conceito de Classe Social em Pierre Bourdieu. Revista Espaço Acadêmico. Ano III, n. 24, Maringá, Maio 2003. Tradução Antônio Marques Bessa.

BALHANA, A. P., PINHEIRO MACHADO, B., WESTPHALEN, C. História do Paraná. Curitiba: Grafipar, 1969. v. 1

BARATA, Alexandre Mansur. Maçonaria, sociabilidade ilustrada e independência do Brasil 17901822. São Paulo: Annablume, 2006.

BELLINI, Moyses. Grande Oriente do Brasil - Paraná: uma síntese de sua história. Ponta Grossa: Gráfica Planeta, 2002.

BONNEWITZ, P. Primeiras lições sobre a sociologia de Pierre Bourdieu. Petrópolis: Vozes, 2003. BOURDIEU, Pierre. Questões de Sociologia, Rio de Janeiro: Marco Zero, 1983 A ilusão biográfica. In: M. A. Ferreira \& J. Amado, Usos e abusos da história oral - Rio de Janeiro: FGV, 1986.

. La noblesse d'État. Grandes écoles et esprit de corps. Paris: Les Éditions de Minuit, 1989. Coisas Ditas, São Paulo: Brasiliense, 1990.

\footnotetext{
${ }^{11}$ Vide a questão das “altas rodas”, ditas por Mills (1968), formadas pela trinca políticos, militares e economia.
} 
Esboço de uma Teoria da Prática. In: ORTIZ, Renato (Org.). A sociologia de Pierre Bourdieu, São Paulo: Editora Ática, 1994, n. 39, p. 46-86. Coleção Grandes Cientistas Sociais.

. Escritos de educação. Rio de Janeiro: Vozes, 1998.

. Coisas ditas. Tradução Cássia R. da Silveira; Denise M. Pegorim. São Paulo:

Brasiliense, 2004.

Meditações pascalinas. Rio de Janeiro: Bertrand Brasil, 2007.

. A economia das trocas simbólicas. São Paulo: Perspectiva, 2009.

BRAGA, Sérgio S. Padrões de organizações das elites partidárias regionais no imediato pósSegunda Guerra no Brasil (1945-1950) e as singularidades da Região Sul. História Unisinos, vol. 5, n. 4, jul./dez/, 2001, pp. 261-297.

BRAGA, Sérgio Soares. Quem foi Quem na Assembléia Constituinte de 1946. Brasília: 2 vols., Centro de Documentação e Informação da Câmara dos Deputados, 1998.

BULST, Neihard. Sobre o Objeto e o método da prosopografia. Politeia: História e Sociedade, Vitória da Conquista, v. 5, n. 1, 2005

BUZATO, José. Grande Oriente do Paraná, nova sede: relato da sua construção. Maringá: edição do autor, 2009.

CANO, Wilson. Da Década de 1920 à de 1930: Transição Rumo à Crise e à Industrialização no Brasil. Revista EconomiA, Brasília(DF), v.13, n.3b, p.897-916, set/dez 2012.

CARNEIRO JÚNIOR, Renato Augusto. Personagens da história do Paraná. Curitiba: SAMP, Museu Paranaense, 2014.

CARVALHO, José Murilo de. A construção da ordem: a elite política imperial. Rio de Janeiro: Civilização Brasileira, 2007.

CARVALHO, William Almeida de. Pequena história da maçonaria no Brasil. Revista de Estudos Históricos de La Masoneria. San José - Costa Rica: v.2, n.1, p. 30-58, mai-nov. 2010.

200 anos de maçonaria no Brasil: cenários e perspectivas.

Revista Ao Zênite. 9 Ed. Brasília: Grande Oriente do Distrito Federal, 2010b. Disponível em: < http://www.godf.org.br/ao_zenyte/ao_zenyte9.pdf>. Acesso em: 07 set 2015.

. Maçonaria no Brasil: análise da produção científica universitária.

Pietre-Stones Review of Freemasonry, 2007. Disponível em: <http://www.freemasonsfreemasonry.com/22carvalho.html> Acesso em: 28 ago 2015.

CASTELLANI, José. Cartilha do Aprendiz. Londrina: A Trolha, 2004. 4. ed.

CASTELlANI, José. CARVALHO, William Almeida de. História do Grande Oriente do Brasil: a Maçonaria na História do Brasil. São Paulo: Madras, 2009. 
CASTRO, Celso. Sociologia e a arte da manutenção de motocicletas. In: Sobre o artesanato intelectual e outros ensaios. Rio de Janeiro: Jorge Zahar Editor, 2009.

CAVALCANTE, Sérgio Roberto. Os antigos manuscritos. Disponível em: <http://www.fraternidadefarroupilha.org/historia/antigosmanuscritos.htm>. Acesso: 20 dez 2013.

CHARLE, Christophe. A Prosopografia ou biografia coletiva: Balanço e perspectivas. In: HEINZ, Flávio (Org.). Por Outra História das elites. Rio de janeiro: FGV, 2006.

CLEBERSON, Max. A Maçonaria e a Proclamação da República. Grande Oriente do Estado de

Goiás: Goiânia, 2012. Disponível em: <
http://www.gobgo.org.br/detalhes_noticia.php?d29a1eac429ca806b8e4cd2a4233480dd29a1eac429c a806b8e4cd2a4233480dd29a1 eac429ca806b8e4cd2a4233480d\&idnt=135> Acesso: 07 mar 2016.

CODATO, A. PERISSINOTTO, R. Por um retorno à Sociologia das elites. Rev. Sociol. Polít., Curitiba: v. 16, n. 30, p. 7-15, jun. 2008

COLUSSI, Eliane. A maçonaria gaúcha no século XIX. Passo Fundo: UPF, 2003.

CONFEDERAÇÃO MAÇÔNICA DO BRASIL. Portal da COMAB na internet. Disponível em: <www.comab.org.br> Vários acessos.

CONFEDERAÇÃO DA MAÇONARIA SIMBÓLICA DO BRASIL. Súmula das assembleias. Brasília: edição própria, 2014.

Portal da CMSB na internet.

Disponível em: <www.cmsb.org.br> Vários acessos.

CORDEIRO, Vita Lopes. A influência política da maçonaria no período da pré-independência do Brasil. Monografia (especialização). Brasília: Centro de Formação, Treinamento e Aperfeiçoamento (Cefor), da Câmara dos Deputados, Curso de Especialização em Instituições e Processos Políticos do Legislativo, 2008.

COSTA, Frederico Guilherme. A Maçonaria e a República. Londrina: Ed. Maçônica A Trolha, 2003.

DAMATTA, Roberto. Relativizando: uma introdução à Antropologia Social. Rocco: Rio de Janeiro: Vozes, 1981.

DORON, Daniel. Freemansory: landmarks and old charges. Tel Aviv: Regular Meeting n. 18 of Montefiore Lodge, 2002. Disponível em: < http://www.freemasons-freemasonry.com/doron.html> Acesso em: 07 set 2015.

DURKHEIM, Émile. As regras do método sociológico. São Paulo: Companhia Editora Nacional, 1960. 2. ed. Educação e sociologia. 11 Ed. São Paulo: Melhoramentos, 1978.

DURÃO, João Ferreira. Pequena história da maçonaria no Brasil. São Paulo: Madras, 2008. 
ELIAS, Norbert; SCOTSON, John L. Os Estabelecidos e os Outsiders: sociologia das relações de poder a partir de uma pequena comunidade. Rio de Janeiro: Jorge Zahar Editor, 2000.

ELIAS, Norbert. O processo civilizador. Rio de Janeiro: Zahar, 2003. 2 v.

FILARDO, José Antônio de Souza. (trad.) O Manuscrito Cooke. (2010). Disponível em: < https://bibliot3ca.files.wordpress.com/2011/03/manuscrito-cooke.pdf> Acesso em: 07 set 2015.

FLORENZANO, Modesto. As revoluções burguesas. São Paulo: Editora Brasiliense,1981 .

FREITAS, Celma. A prática em Bourdieu. Revista Científica FacMais, Inhumas, Volume. I, Número I. Ano 2012/1º Semestre.

GAGLIANONE, Paulo César. A introdução do rito moderno no Brasil. Supremo conselho do Rito Moderno: Rio de Janeiro, 1994. Disponível em: < https://bibliot3ca.wordpress.com/a-introducaodo-rito-moderno-no-brasil/>. Acesso em: 20 ago 2015.

GRANDE LOJA DO PARANÁ. Portal da GLP na internet. Disponível em: <www.glp.org.br> Vários acessos.

GRANDE ORIENTE DO BRASIL. Portal do GOB na internet. Disponível em: 〈www.gob.org.br> Vários acessos.

GRANDE ORIENTE DO PARANÁ. Portal do GOP na internet. Disponível em: <www.gop.org.br> Vários acessos.

GOMES, Laurentino. 1822: como um homem sábio, uma princesa triste e um escocês louco por dinheiro ajudaram D. Pedro a criar o Brasil - um país que tinha tudo para dar errado. Rio de Janeiro: Nova Fronteira, 2010.

GONÇALVES, N. G. Pierre Bourdieu: educação para além da reprodução. Petrópolis: Vozes, 2010.

GOULART, Mônica Helena Harrich Silva. A dança das cadeiras: análise do jogo político na Assembleia Legislativa do Paraná (1889-1930). Jundiaí: Paco Editorial, 2014.

O poder local e o coronelismo do Estado do Paraná (1880-1930). Dissertação (mestrado). Curitiba: Programa de Pós-Graduação em Sociologia, Universidade Federal do Paraná, 2004.

HAMILL, John. Teorias sobre a origem da Maçonaria. Revista Internacional Hiram Abif. Mar del Plata: n. 9/10, nov-dez. 2000. Disponível em: < https://bibliot3ca.wordpress.com/teorias-sobre-aorigem-da-maconaria/> Acesso em: 07 set 2015.

HAYWOOD, H.L. Como a maçonaria operativa se transformou na maçonaria especulativa: o período de transição. Outubro, 2013. Disponível em: < http://joseroberto735.blogspot.com.br/2013/10/como-maconaria-operativa-se-transformou.html> Acesso em: 07 set 2015.

HEINZ, Flávio M. Por outra história das elites. Rio de Janeiro: Editora FGV, 2006.

HEINZ, Flávio M. CODATO, Adriano. A prosopografia explicada para cientistas políticos. In: 
CODATO, Adriano \& PERISSINOTO, Renato. Como estudar elites? Curitiba: Editora UFPR, 2015.

HEYWOOD, Andrew. Ideologias políticas: do liberalismo ao fascismo. v.1. São Paulo: Editora Ática, 2010.

HOBSBAWN, ERIC; RANGER, Terence (orgs.). A invenção das tradições. Rio de Janeiro: Paz e Terra, 1984.

HUNTER, Floyd. Community Power Structure: A Study of Decision Makers. Garden City: 1963, Anchor Books.

ISMAIL, Kennyo. Desmistificando a maçonaria. São Paulo: Universo dos Livros, 2012.

A verdadeira história dos primórdios da maçonaria no Brasil. Blog "No Esquadro": Novembro, 2011. Disponível em: < http://www.noesquadro.com.br/2011/11/verdadeirahistoria-dos-primordios-da.html>. Acesso em: 20 ago 2015.

. O que é filosofismo. Blog "No Esquadro": Fevereiro, 2012. Disponível em: http://www.noesquadro.com.br/2011/02/o-que-e-filosofismo.html. Acesso em: 10 mai 2014.

. História da maçonaria para adultos. Blog "No Esquadro": Março, 2012. Disponível em: <http://www.noesquadro.com.br/2012/03/historia-da-maconaria-paraadultos.html>. Acesso em: 19 dez 2013.

A colonização maçônica inglesa: na contramão dos princípios maçônicos. Blog

"No Esquadro": $\quad$ Setembro, 2014. Disponível em: <
http://www.noesquadro.com.br/2014/09/colonizacao-maconica-inglesa-na-contramao-dosprincipios-maconicos.html>. Acesso em: 20 ago 2015.

LAHIRE, B. Reprodução ou prolongamentos críticos? Educação \& Sociedade, Campinas, v. 23, n. 78, p. 37-55, abr. 2002.

LAIBIDA, Luiz Demétrio Janz. Representação teatral: Assembleia Legislativa do Estado do Paraná - institucionalismo e vetos. Dissertação (mestrado). Curitiba: Programa de Pós-Graduação em Sociologia, Universidade Federal do Paraná, 2007.

LEADBEATER, C.W. Pequena história da maçonaria. 12. Ed. São Paulo: Editora Pensamento, 2012.

LÉVI-STRAUSS, Claude. Mito e significado. Tradução Antônio Marques Bessa. Coletivo Sabotagem, 1978.

LOJA MAÇÔNICA SÃO PAULO 43. Portal da Loja Maçônica São Paulo n. 43. Disponível em: < http://www.lojasaopaulo43.com.br/maconaria.php>. Acesso em 19 Jan 2014.

LOVE, Joseph L. and BARICKMAN, Bert. J. "Regional Elites". In CONNIFF, Michael L. and MCCANN, Frank D (eds.), Modern Brazil: Elites and Masses in Historical Perspective, Nebraska, The University of Nebraska Press, 1991, pp. 3-22. 
MACHADO, Vanderlei Hermes. Política e estruturas de parentesco de Campo Largo (1871-2004). Dissertação (mestrado). Curitiba: Programa de Pós-Graduação em Sociologia, Universidade Federal do Paraná, 2005.

MARCELINO, Marcelo Gonçalves. Intervencionismo estatal e ideologia desenvolvimentista na construção do sistema de planejamento do Paraná (1972-1982). Dissertação (mestrado). Curitiba: Programa de Pós-Graduação em Sociologia, Universidade Federal do Paraná, 2006.

MATOS, Carlos Eduardo; NASTACCI, Samantha; FIGUEIREDO DE SÁ, Davi. A maçonaria na história. Rio de Janeiro: Ediouro Publicações, 2015.

MILLS, C. Wright. A Elite do Poder. Rio de Janeiro: Zahar, 1968. A imaginação sociológica. Rio de Janeiro: Zahar Editores, 1965. Sobre o artesanato intelectual e outros ensaios. Rio de Janeiro: Jorge Zahar

Editor, 2009.

MONTAGNER, Miguel Ângelo. Trajetórias e biografias: notas para uma análise bourdieusiana. Porto Alegre: Revista Sociologias, ano 9, nº 17, jan/jun, 2007. P. 204-264.

MOREL, Marco; SOUZA, Françoise Jean de O. O poder da maçonaria. A história de uma sociedade secreta no Brasil. Rio de Janeiro: Nova Fronteira, 2008.

MOSCA, Gaetano. A classe dirigente. In: Souza, Amaury de (org.). Sociologia Política. Rio de Janeiro: Zahar Editores. Col. "Textos Básicos de Ciências Sociais”, 1966.

História das doutrinas políticas: desde a antiguidade. Rio de Janeiro: Zahar,

1968.

NETO, Elias Mansur. O que você precisa saber sobre maçonaria. São Paulo: Universo dos Livros, 2005.

OLIVEIRA, Roberto Cardoso de. O Trabalho do Antropólogo. Brasília/São Paulo: Paralelo Quinze/Editora da UNESP, 1998.

OLIVEIRA, Ricardo Costa de. O silêncio dos vencedores. Genealogia, classe dominante e Estado no Paraná. Curitiba: Moinho do Verbo, 2001.

(org) Análise dos parlamentares paranaenses na entrada do Século

XXI. Curitiba: APUFPR-SSind, 2002.

(org) A construção do Paraná moderno - políticos e política no governo do Paraná de 1930 a 1980. Curitiba: Imprensa Oficial, 2004.

Na teia do nepotismo: sociologia política das relações de parentesco e poder político no Paraná e no Brasil. Curitiba: Insight, 2012. (org) Estado, Classe dominante e parentesco no Paraná. Blumenau:

Nova Letra, 2015. 
PARETO, Vilfredo. Tratado de sociologia geral. In: Rodrigues, José Albertino (org.). Vilfredo Pareto: sociologia. São Paulo: Ática. Col. “Grandes Cientistas Sociais”, v. 43, 1984.

PERISSINOTTO, Renato. Notas metodológicas sobre o estudo de elites. Curitiba: Nusp, 2003.

PIRES, Joaquim da Silva. A cisão maçônica brasileira de 1927. Londrina: A Trolha, 2015.

PROBER, Kurt. Achegas para a história da maçonaria paranaense. Curitiba: Ex-Libris, 1978.

RESENDE, Daiane Carnelós. Elementos decisivos na construção da posição e ação política de Roberto Requião de Mello e Silva. Jundiaí: Paco Editorial, 2014.

RESENDE, Roberta Carnelós. Gênero, performance eleitoral e perfis: uma análise da Assembleia Legislativa do Paraná (1998 a 2006). Dissertação (mestrado). Curitiba: Programa de Pós-Graduação em Sociologia, Universidade Federal do Paraná, 2009.

RODRIGUES, Leôncio Martins. Partidos, ideologia e composição social: um estudo das bancadas partidárias na Câmara dos Deputados. São Paulo, Edusp, 2002.

SANT'ANNA, Anderson de Souza. SOUZA, Iago Vinicius Avelar. A sociologia de Bourdieu: aplicações e potencialidades em pesquisas em administração. Bento Gonçalves: XXIII Enangrad Encontro Nacional dos Cursos de Graduação em Administração, 2012.

SANTIN, Janaína. LORENZONI, André Luiz. Liberalismo e Direito na formação de bacharéis e instituições políticas e jurídicas no Brasil imperial. MÉTIS: história \& cultura - v. 12, n. 23, p. 4964, jan./jun.2013

SCHÜLER, Octacílio Sobrinho. Uma luz na história: a formação e o sentido da COMAB. Florianópolis: Editora cultural O Prumo SC Ltda, 1998.

Florianópolis: Editora Letras Contemporâneas, 1999.

SPOLADORE, Hercule. História da maçonaria paranaense no século XIX. Londrina: Ruahgraf, 2007.

. Comentários sobre os graus primitivos da Maçonaria. São Paulo: VII

Jornada Maçônica Zona Leste de São Paulo, 2003. Disponível em: < http://deusecaridadenona.com.br/comentprimitivos.pdf>. Acesso em: 07 set 2015.

STONE, Lawrence. Prosopografia. Revista de Sociologia e Política. Curitiba: v. 19, n. 39, p. 115137, jun. 2011.

TABATCHEIK, Guilherme. Desvendando os Diários Secretos: uma análise do uso dos cargos em comissão da Assembleia Legislativa do Paraná (2002-2006). Dissertação (mestrado). Curitiba: Programa de Pós-Graduação em Sociologia, Universidade Federal do Paraná, 2015.

VALENCIANO, Tiago. Qual carreira? O perfil dos grão-mestres da maçonaria paranaense. Porto Alegre: V Seminário Nacional de Ciência Política, 2013. 
VALENCIANO, Tiago \& LEAL E SILVA, Rafael Egídio. Política Brasileira: como entender o funcionamento do Brasil. Astorga: Editora Sahar, 2015.

WEBER, Max. Ciência e Política. Duas Vocações. São Paulo: Editora Cultrix, 1998.

. Economia e sociedade: fundamentos da sociologia compreensiva. V.1 3. Ed. Brasília: UnB, 1994.

ZUCOLI, Hiran Luiz. A Maçonaria no Paraná. Curitiba: edição do autor, 2001.

Museu Maçônico Paranaense. Portal do Museu na internet. Disponível em:

<www.museumaconicoparanaense.com> Vários acessos.

\title{
COMPASS, THE BRACKET AND DISCREET ORDER: SOCIOLOGICAL PROFILE OF GRAND MASTERS OF FREEMASONRY PARANAENSE
}

\begin{abstract}
This work is abstract destination analyze collectively from prosopographical method, the profile of the Grand Masters of the Grand Orient of Brazil - Paraná (GOB / PR), the Great Paraná shop (GLP) and the Grand Orient of Parana ( GOP), in order to define a strategic elite, formed from specific individuals and social capital, as a profession, Masonic career and social inclusion. The question of this work (which is the socio-professional profile of the Grand Masters of Freemasonry Paranaense) is intended to understand this strategic social group measuring the limits of presence and cohesive social activities in Paraná. First, we made a report on Freemasonry in Paraná and its development. Then we discuss the possibilities of prosopographical method and its use as a sociological technique. Forward there is the study of the profiles of these individuals, investigating the Masons recruitment patterns in question, with respect to social origin, professional, career in the institution and the relationship of their professional activities with society. Finally a close examination of the results will be held - still under the aegis of the research problem: to what extent the collective biography of the Grand Masters relates to the Paraná society and social status, professional, political and institutional.
\end{abstract}

Key-words: Masonry. Prosopography. Masonry Paranaense. Grand Masters. 